\title{
Myopic versus Far-Sighted Behaviors in Dynamic Supply Chain Coordination through Advertising with Reference Price Effect
}

\author{
Yafei Zu and Lianghua Chen \\ School of Economics and Management, Southeast University, Nanjing 211189, China \\ Correspondence should be addressed to Yafei Zu; zuyafei@seu.edu.cn
}

Received 6 January 2017; Revised 2 April 2017; Accepted 24 April 2017; Published 18 May 2017

Academic Editor: Lu Zhen

Copyright ( 2017 Yafei Zu and Lianghua Chen. This is an open access article distributed under the Creative Commons Attribution License, which permits unrestricted use, distribution, and reproduction in any medium, provided the original work is properly cited.

To better understand the different effects of the myopic and far-sighted behaviors on the advertising coordination in dynamic supply chain, this paper takes the reference price effect into consideration and formulates four differential game models for the two-level supply chain composed of a manufacturer and a retailer in the situation of Stackelberg game. In our models, the market demand is assumed to be affected by the goodwill, reference price, and the advertising investment, in which the advertising investment can promote the construction of goodwill and such goodwill can further enhance the reference price. The results show that the participating members in the supply chain should invest more in advertisement to improve the goodwill and the relative reference price reflected in the minds of consumers. A far-sighted manufacturer will invest more in the advertisement and charge a higher wholesale price regardless of the behavior choice of the retailer. However, such kind of ignorance leads to different results on the retail pricing strategies of the retailer. The numerical analyses are given in the end to verify the effectiveness of the conclusions which provide the theoretical support to the dynamic supply chain coordination in practice.

\section{Introduction}

Against the backdrop of complex environment and for the purpose of long-term profit maximization, participating members in the supply chain should act as far-sighted decision-makers. However, according to the agency theory, managers pay more attention to the short-term profits as it can maximize the benefits of their own. To clarify the myopic and far-sighted behaviors and their relative effects in dynamic supply chain, many scholars formulated models under the assumption that the myopic decision is made considering the current instantaneous profit, while the far-sighted decision focuses on the performance in the long run and indicated that it is difficult for the enterprises to make decisions considering the long-term performance (Chakravarti et al. [1]; Hauser et al. [2]; Liu et al. [3]). Therefore, in the aspect of supply chain, it is a kind of the myopic behavior when the participating member ignores the further influence of her current decision on the other factors including the microscopic supply chain factors and the macroscopic environmental factors, and she thinks the environment is static (Jørgensen et al. [4]; Benchekroun et al. [5]). On the contrary, when the participating member in the supply chain takes the further influence of her decision on the other factors into consideration and thinks the environment is dynamic, she will be regarded as a far-sighted decision-maker. Previous researches about effects of the far-sighted/myopic behavior choice on the marketing strategies including the pricing, profits, and quality are very common. However, there are fewer papers focusing on the effects of such behavior choice on the operation strategies such as goodwill and advertisement. To fill in this researching gap and build a bridge between the operation and marketing strategies considering the far-sighted/myopic behaviors of the participating members in the supply chain, our paper formulates a dynamic game model to study the relationship between the behaviors choice and the operation-marketing strategies.

Market demand usually can be affected by many factors, in which the advertising and reference price are the most significant ones. According to the classical economics theory, 
the lower the price is, the higher the market demand will be. However, when the concept of reference price is introduced into the analysis, things will be changed (Fibich et al. [6]). In this point of view, when the market price is lower than the reference price, consumers can generate a kind of feeling that they gain and tend to purchase more products, so that the market demand will increase. On the other hand, advertising in the dynamic supply chain can be used as the effective tool to promote the final demand through the enhancement of goodwill in the minds of consumers. Considering the interaction of advertising and reference price in the dynamic supply chain, Zhang et al. [7] put forward a model and assumed that both of the reference price and market demand are influenced by the advertising efforts of participating members, which is not conformed to the practice for the reason that consumers cannot perceive the efforts of enterprises. The manufacturer's advertising investment only has the influence on the goodwill, through which it affects the reference price in the minds of consumers. On the other hand, market demand can be influenced by both the goodwill and the difference between the reference and market price. At the same time, the advertising investment has an instantaneous effect on the market demand. Therefore, taking the integrated effect of advertising and reference price into consideration is necessary to analyze the myopic/far-sighted behaviors in dynamic supply chain coordination. This paper is different from the previous researches for that we take the integrated effect of the reference price and goodwill on the supply chain into consideration and analyze the transmission mechanism from the advertising investment to the goodwill and then to the reference price, finally affecting the market demand.

According to the background analyzed above, this paper pays attention to the difference between myopic and farsighted behaviors in dynamic supply chain coordination. It aims to solve the problem of the advertising investment and pricing strategies in the supply chain in the myopic and far-sighted situations with reference price and perceived goodwill effect and analyzes the effect of the revenue sharing mechanism between the manufacturer and the retailer based on the differential game theory. This paper is arranged as follows. In Section 2, the relevant literature is reviewed. Section 3 presents the framework of models. In Sections 4 and 5, four differential game models are formulated according to the different combinations of the myopic/farsighted behaviors in the supply chain. Then Section 6 presents the comparisons between different situations and Section 7 presents the conclusions.

\section{Literature Review}

The advertising coordination model in supply chain was first put forward by Dorfman and Steiner [8] to study the effects of advertising on the total revenues. However, the specific kinds of the advertising effects on the revenues are different in these previous studies (Chioveanu [9]). In the dynamic view, He et al. [10] constructed a dynamic differential model to depict the interaction of pricing and advertising strategies in the dynamic supply chain; they concluded the equilibriums in the environment of uncertainty. Considering the game structure (noncooperation and cooperation), Xie and Wei [11] found that both of the advertisement and sales prices have an influence on market demands. Chaab and Rasti-Barzoki [12] also compared the advertising difference between cooperative and Stackelberg game. Paying attention to the participating members, Karray and Amin [13] indicated that when there are several competing retailers in the supply chain, the cooperative advertising may not lead to the optimal situation. In the aspect of the mediating variable, Feng et al. [14] found that goodwill plays a significant role in the relationship between the pricing decision and the advertising strategy and a lower price or a higher goodwill can lead to a higher market demand. Zhang et al. [7] divided the type of advertising into the national one conducted by the manufacturer and the local one conducted by the retailer. They found that it is wise to generate more national advertising under the condition that consumers are heavily influenced by the reference price in their minds. Those papers above study the effect of advertising on the revenue from different perspectives; however, there are few studies considering the behavior choice of the participating members in the supply chain. The behaviors of the participating members in the supply chain, especially the myopic or far-sighted behaviors, play a critical role in the consumers' preference and decisions. Our study pays more attention to the behavior choice of the manufacturer and the retailer in the supply chain and introduces the goodwill as the mediating variable between the advertising and price variable to analyze the integrated effects on the final market demand.

Reference price plays an important role in the purchasing decisions of consumers and the relative market demands; it has attracted increasing attention recently. The first systematic researching framework of the reference price was put forward by Lattin and Bucklin [15]; they combined the concepts of adaptation-level theory and assimilation contrast theory to study the reference price effects. Considering that the consumers can remember the historical price of the products and the relative anchoring effects, Popescu and Wu [16] formulated a model with multiperiods to study the impacts of reference price on the market demand. They indicated that enterprises should focus on the long-term performance rather than the immediate profits. However, they neglected the special structure in the supply chain. Geng et al. [17] extended their models to the problem of dynamic pricing in the supply chain by introducing the wholesale price of the manufacturer and the advertising frequency. Fibich et al. [18] suggested that the optimal sales price remains stable and tends to be a constant in the situation where losses effects on the market demand are higher than the gains effects. Their conclusion was consistent with the research of Popescu and Wu [16]. Nasiry and Popescu [19] introduced the behavioral factor into the reference price model based on the peak-end anchoring effect; however, they just assumed that the function of reference price is discrete weighted average between the latest price and lowest price. Zhang et al. [20] formulated a differential equation in a bilateral monopoly market to study the pricing strategies in two distribution channels; they concluded that it is beneficial for the competitive supply chain to boost a higher initial 
reference price. Benchekroun et al. [5], Martín-Herrán et al. (2012) [21], and Martín-Herrán and Taboubi (2015) [22] studied the reference price and the relative pricing strategies in the context of the supply chain. Most of the previous papers considered the reference price as an exponentially decaying weighted average of the past observed prices and neglected the operation factors which affect the reference price. Therefore, based on the classical identification of the reference price, our paper introduces the effect of perceived goodwill which is influenced by the advertisement. On the other hand, with the development of behavior science, the behaviors of the participating members play an increasing important role in the decision-making process of the supply chain. Therefore, studying the integrated effects of reference price and advertising in the context of the behaviors of the participating members in dynamic supply chain is quite important and urgent.

Among the researches about supply chain coordination, most of them focused on the myopic behaviors. In the model of Taboubi and Zaccour [23], a two-level supply chain composed of a manufacturer and a myopic retailer was assumed. They indicated that when the retailer is myopic, she tends to not work hard and chooses a lower sales price, so the manufacturer has to raise her effort to solve the problem. Chiang [24] found the same results as Taboubi and Zaccour [23] and concluded that enterprises should focus on the long-term performance for the reason that the current profit may be myopic and it is harmful to the operation. However, the diffusion model of Gutierrez and $\mathrm{He}$ [25] showed that, faced with a myopic retailer, the manufacturer will be beneficial instead, which is quite different from the results of Taboubi and Zaccour [23] and Chiang [24]. To further compare the difference between the myopic and farsighted behaviors, Benchekroun et al. [5] formulated a model to investigate the situations in the bilateral monopoly market considering the effect of reference price. They found that both the manufacturer and the retailer can be beneficial to their myopic decisions under the condition that the reference price is low enough. In the aspect of price-quality relationship and the behavior choice, Liu et al. [3] formulated a dynamic pricing model and indicated that, in the twolevel supply chain, the manufacturer always tends to choose the far-sighted behavior while the retailer will not. They also found that the far-sighted behaviors lead to the lower sensitivity to the quality and the higher sensitivity to the price in the market demand. In our model, we formulate four combinations of the participating members with different behaviors based on the Stackelberg game in the supply chain. Our research differs from the previous papers in that the comprehensive effects of the advertising investment and the reference price are considered, and we also study the effects of far-sighted/myopic behaviors on the advertising-pricing relationship in the context of the dynamic supply chain.

\section{Model Framework}

Consider a two-level dynamic supply chain which is composed of a manufacturer and a retailer, in which the manufacturer occupies a dominant position for the reason that she masters the core technology. Hence, in Stackelberg game situation, the manufacturer plays the role of leader in the whole supply chain, while the retailer is the follower. We present the analyses of myopic and far-sighted situations, respectively, considering that the behavior tendencies of the manufacturer and the retailer have an important influence on their optimal strategies. Both of them coordinate with each other to promote the market demand in the long run. The game sequence is as follows: firstly, the manufacturer makes a decision about her investment level on advertising and the wholesale price to the retailer. Then, after observing the action of manufacturer, the retailer decides the retail price of the product. Also, the consumers take an important role in the game for their behaviors have a significant influence on the market demand. According to the practice, we assume that the decisions of consumers are influenced by the reference price in their minds as well as the goodwill of the products. We mainly pay attention to the influence of myopic and far-sighted strategies with advertising coordination and reference price effect in the supply chain, regardless of the inventory, shortage cost, and any other factors affecting the demand. At the same time, to better analyze the effect of behavior choice of the participating members in the supply chain on the marketing-operation relationship, the specific strategies of the manufacturer and the retailer are assumed stationary; that is, once they decide to choose a certain kind of the behavior (including the far-sighted one and myopic one), they will not change it in the game process. Our analysis is based on the assumption of perfect information, and the members in the supply chain are all rational decision-makers. The mechanism of this problem can be described as in Figure 1.

The notations and definitions of the differential game analysis used in this paper are shown in "Notations and Definitions" section.

Based on the practical background and relative settings above, most of the advertisements are invested by the manufacturer for she knows more about the products she produces. The manufacturer advertises on the national scale to shape the images and promote the purchasing behaviors of consumers. The investment level is varying with the time. When the manufacturer carries out her relative advertising investment, consumers will perceive this kind of signal which shows that this enterprise is reliable and their products are good, so it leads to an increasing goodwill in the minds of consumers. Consistent with this characteristic and based on the classical Nerlove-Arrow framework, we assume that the goodwill of the product can be written as follows:

$$
\dot{g}(t)=\delta[A(t)-g(t)], \quad g(0)=g_{0} \geq 0
$$

On the other hand, a higher goodwill of the enterprise is much helpful to form a favorable image, which can increase the reference price in the minds of consumers. In this way, consumers will think that the product is good and it deserves to spend more money. Also, according to the classical studies on the reference price, consumers will perceive a sense of loss when they find that the market price is higher than the reference price. Under this condition, consumers tend 




FIGURE 1: Mechanism of supply chain coordination through advertising with reference price effect.

to increase the reference price in their minds. Hence the reference price differential model can be formulated as follows:

$$
\dot{r}(t)=\gamma[p(t)-r(t)]+\sigma g(t), \quad r(0)=r_{0} \geq 0 .
$$

This formulation is obtained taking into account that the reference price is formed as a continuous weighted average of past prices observed with an exponentially decaying weighting function and the perceived goodwill of the consumers. It seems different from the basic specification of the reference price in which the reference price coincides with the retail price in the end. The basic one neglects the effect of the goodwill on the reference price. According to the research of Zhang et al. [7], consumers tend to pay more for the products produced by the enterprises with nice goodwill. Therefore, in our model, specification $r_{\mathrm{ss}}=p+\sigma g_{\mathrm{ss}} / \gamma$ will hold for the reason that not only the retail price has the effect on the reference price in the minds of consumers, but also the goodwill of the product can affect the reference price in the long run. Our setting coincides with the previous studies such as Lu et al. [26], Zhang et al. [27].

As mentioned in many previous studies, our identification indicates that the demand will decease with the increase of actual price; a standard assumption represented the economic role of the price. Consumers will perceive a sense of gain when they find that the market price is lower than the reference price in their minds, so that it is positively related to the market demand. At the same time, consumers always tend to purchase the products with a higher goodwill; therefore, the goodwill also has the positive relationship with the market demand. The advertising investment of the manufacturer has the positive instant effect on the market demand. Thus we assume that the market demand $D(t)$ at time $t$ can be expressed as follows:

$$
\begin{aligned}
D(t)= & D_{0}-\varepsilon p(t)+\alpha[r(t)-p(t)]+\beta g(t) \\
& +\lambda A(t) ;
\end{aligned}
$$

here let $\alpha+\varepsilon=\theta$; hence, the market demand function can be written as follows:

$$
D(t)=D_{0}+\alpha r(t)+\beta g(t)-\theta p(t)+\lambda A(t) .
$$

Based on the background and relative settings above, a form of quadratic cost function is assumed to depict the cost of effort on advertising of the manufacturer at time $t$; therefore $C_{i}(i=M, R)$ can be written as follows:

$$
C=\frac{\mu}{2} A^{2}(t) .
$$

Considering that there exists the marginal diminishing effect in the advertising effort, the manufacturer tends to not advertise continuously. Therefore, according to the previous literature, an upper bound (a constant which is high enough, denoted as $M$ ) of the effort is assumed, so that $0 \leq A(t) \leq M$.

\section{Feedback Stackelberg Equilibrium of Myopic Manufacturer}

4.1. Situation of Myopic Retailer. In the context of the dynamic supply chain, both the manufacturer and the retailer ignore the future impacts of their marketing and operation decisions on the market demand and act in a myopic way in this situation. The objective function of the manufacturer and the retailer can be written as follows:

$$
\begin{aligned}
J_{M} & \\
& =\int_{0}^{\infty} e^{-\rho t}\left\{[\varphi p(t)+w(t)-c] D(t)-\frac{\mu}{2} A^{2}(t)\right\} d t, \\
J_{R} & =\int_{0}^{\infty} e^{-\rho t}\{[(1-\varphi) p(t)-w(t)] D(t)\} d t .
\end{aligned}
$$

Therefore, when the participating members in the supply chain choose to ignore the dynamic relationships including the goodwill and the reference price (i.e., they behave myopically), their objective functions with $g(0)=g_{0} \geq 0, r(0)=$ $r_{0} \geq 0$ can be expressed as follows:

$$
\begin{aligned}
& \max _{w(\cdot), A(\cdot)}\{[\varphi p(t)+w(t)-c] \\
& \cdot\left[D_{0}+\alpha r(t)+\beta g(t)-\theta p(t)+\lambda A(t)\right]-\frac{\mu}{2} \\
& \left.\cdot A^{2}(t)\right\}
\end{aligned}
$$




$$
\begin{aligned}
\max _{p(\cdot)}\{[(1-\varphi) p(t)-w(t)] \\
\left.\cdot\left[D_{0}+\alpha r(t)+\beta g(t)-\theta p(t)+\lambda A(t)\right]\right\} .
\end{aligned}
$$

As the role of the follower in the Stackelberg game, the reaction function of the retailer will be calculated first. The retail price can be expressed as a function of the wholesale price and the advertising investment of the manufacturer. In this situation, both the retailer and manufacturer behave myopically. Hence, differentiating (7) with respect to the decision variable $p$ and equating it to zero, the retail price of the product can be expressed as follows:

$$
p^{*}=\frac{(1-\varphi)\left(D_{0}+\alpha r+\beta g+\lambda A\right)+\theta w}{2 \theta(1-\varphi)}
$$

Based on the function of optimal retail price, insert equation (8) into the objective function of the manufacturer and differentiate it with respect to the decision variable $w$ and equate it to zero (same as decision variable $A$ ); the wholesale price and the advertising investment can be expressed as follows:

$$
\begin{aligned}
& w^{*}=\frac{(1-\varphi)^{2}\left(D_{0}+\alpha r+\beta g+\lambda A\right)+(1-\varphi) c \theta}{(2-\varphi) \theta} \\
& A^{*}=\frac{\left(D_{0}+\alpha r+\beta g\right) \varphi \lambda+(w-c) \theta \lambda}{2 \theta \mu-\varphi \lambda^{2}}
\end{aligned}
$$

Then they will be taken into the expression of the decision variable of the retailer. Therefore, the optimality in this situation can be expressed in Proposition 1 as follows.

Proposition 1. In the situation of the Stackelberg game consisting of a myopic manufacturer and a myopic retailer, the optimal retail price, wholesale price, and advertising investment can be expressed as follows:

$$
p^{*}=\frac{2(3-2 \varphi)\left(D_{0}+\alpha r+\beta g\right) \theta \mu-2 \mu c \theta^{2}}{2 \theta\left[2(2-\varphi) \theta \mu-\lambda^{2}\right]}
$$

$$
\begin{aligned}
& w^{*} \\
& =\frac{2(1-\varphi)^{2}\left(D_{0}+\alpha r+\beta g\right) \mu-(1-\varphi)\left(2 \mu \theta-\lambda^{2}\right) c}{2(2-\varphi) \theta \mu-\lambda^{2}}, \\
& A^{*}=\frac{\left(D_{0}+\alpha r+\beta g\right) \lambda-c \theta \lambda}{2(2-\varphi) \theta \mu-\lambda^{2}} .
\end{aligned}
$$

As Proposition 1 showed, although both the manufacturer and the retailer are assumed myopic in this situation, the optimal decision variables are still related to the two state variables. Hence, we get the time path of accumulated goodwill and reference price of the product as follows:

$$
\begin{aligned}
g(t)= & g_{\mathrm{ss}}+\left(g_{0}-g_{\mathrm{ss}}\right) e^{-\delta t}, \quad g(0)=g_{0}, \\
r(t)= & r_{\mathrm{ss}}+\left(r_{0}-r_{\mathrm{ss}}\right) e^{-\gamma t} \\
& +\frac{\sigma\left(g_{0}-g_{\mathrm{ss}}\right)}{\gamma-\delta}\left(e^{-\delta t}-e^{-\gamma t}\right), \quad r(0)=r_{0},
\end{aligned}
$$

where $\gamma \neq \delta$ and both of them are the real eigenvalues of the dynamic system matrix and $g_{\text {ss }}$ and $r_{\text {ss }}$ refer to the steady states of the goodwill and the reference price, respectively, given by $g_{s s}=A^{*}, r_{s s}=p^{*}+\sigma g_{s s} / \gamma$. Then substitute the equilibriums above into the objective function of the manufacturer and the retailer in sequence; we can get their optimal profits as follows:

$$
\begin{aligned}
J_{M} & =\left[\varphi p^{*}+w^{*}-c\right]\left[D_{0}+\alpha r_{\mathrm{ss}}+\beta g_{\mathrm{ss}}-\theta p^{*}+\lambda A^{*}\right] \\
& -\frac{\mu}{2}\left(A^{*}\right)^{2}, \\
J_{R} & =\left[(1-\varphi) p^{*}-w^{*}\right] \\
& \cdot\left(D_{0}+\alpha r_{\mathrm{ss}}+\beta g_{\mathrm{ss}}-\theta p^{*}+\lambda A^{*}\right) .
\end{aligned}
$$

4.2. Situation of Far-Sighted Retailer. In this situation, we assume a supply chain consisting of a myopic manufacturer and a far-sighted retailer. The retailer is assumed far-sighted so that she will take the dynamic relationships of reference price and goodwill into the consideration when she makes the decision. There exist constraint conditions in her optimal programming model. The objective function of the retailer can be written as follows:

$$
\begin{array}{ll}
\max _{p(\cdot)} & \int_{0}^{\infty} e^{-\rho t}\left\{[(1-\varphi) p(t)-w(t)]\left[D_{0}+\alpha r(t)+\beta g(t)-\theta p(t)+\lambda A(t)\right]\right\} d t \\
\text { s.t. } & \dot{g}(t)=\delta[A(t)-g(t)] \\
& \dot{r}(t)=\gamma[p(t)-r(t)]+\sigma g(t) .
\end{array}
$$

In the stationary Stackelberg game, the continuous differentiable function with bounds should be carried out as the sufficient condition of the equilibrium strategies. Denote the equilibrium current profit of the retailer after time $t$ in 
Hamilton-Jacobi-Bellman equation (hereinafter referred to as HJB equation) as $V_{R}$; then, for all $r(t) \geq 0, g(t) \geq 0, V_{R}$ should meet the equation below:

$$
\begin{aligned}
\rho V_{R} & =\max _{p \geq 0}\{[(1-\varphi) p-w] \\
& \cdot\left(D_{0}+\alpha r+\beta g-\theta p+\lambda A\right)+V_{1 R}^{\prime} \delta(A-g) \\
& \left.+V_{2 R}^{\prime}[\gamma(p-r)+\sigma g]\right\} .
\end{aligned}
$$

Since the manufacturer is assumed myopic, there will be no constraint condition in her optimal programming model. Hence the objective function of the manufacturer can be written as follows:

$$
\begin{aligned}
& \max _{w(\cdot), A(\cdot)}\{[\varphi p(t)+w(t)-c] \\
& \cdot\left[D_{0}+\alpha r(t)+\beta g(t)-\theta p(t)+\lambda A(t)\right]-\frac{\mu}{2} \\
& \left.\cdot A^{2}(t)\right\} .
\end{aligned}
$$

Same as the calculation sequence shown in Section 4.1, we work out the retailer's reaction function of the retail price first. In this situation, the manufacturer is myopic while the retailer behaves farsightedly. Hence, differentiate (14) with respect to the decision variable $p$ and equate it to zero; the retail price of the product can be expressed as follows:

$$
p^{*}=\frac{(1-\varphi)\left(D_{0}+\alpha r+\beta g+\lambda A\right)+\theta w+\gamma V_{2 R}^{\prime}}{2 \theta(1-\varphi)} .
$$

Insert the optimal retail price into the objective function of the manufacturer and differentiate it with respect to the decision variable $w$ and equate it to zero (same as decision variable $A$ ); hence, the wholesale price and the advertising investment can be expressed as follows:

$$
\begin{aligned}
& w^{*} \\
& =\frac{(1-\varphi)^{2}\left(D_{0}+\alpha r+\beta g+\lambda A\right)+(1-\varphi) c \theta-\gamma V_{2 R}^{\prime}}{(2-\varphi) \theta}, \\
& A^{*}=\frac{\left(D_{0}+\alpha r+\beta g\right) \varphi \lambda+(w-c) \theta \lambda}{2 \theta \mu-\varphi \lambda^{2}} .
\end{aligned}
$$

Then they will be taken into the expression of the decision variable of the retailer. Therefore, the optimality in the situation of the Stackelberg game consisting of a myopic manufacturer and a far-sighted retailer can be expressed as follows:

$$
\begin{aligned}
p^{*}= & \frac{(1-\varphi)\left(D_{0}+\alpha r+\beta g\right)+\gamma V_{2 R}^{\prime}}{2(1-\varphi) \theta}+\frac{\left(D_{0}+\alpha r+\beta g\right) \lambda^{2}-c \theta \lambda^{2}-\lambda^{2} \gamma V_{2 R}^{\prime}}{4(2-\varphi) \theta^{2} \mu-2 \theta \lambda^{2}} \\
& +\frac{2(1-\varphi)^{2}\left(D_{0}+\alpha r+\beta g\right) \theta \mu+(1-\varphi)\left(2 \theta \mu-\lambda^{2}\right) \theta c-\left(2 \theta \mu-\varphi \lambda^{2}\right) \gamma V_{2 R}^{\prime}}{2(1-\varphi)\left[2(2-\varphi) \theta \mu-\lambda^{2}\right] \theta}, \\
w^{*}= & \frac{2(1-\varphi)^{2}\left(D_{0}+\alpha r+\beta g\right) \theta \mu+(1-\varphi)\left(2 \theta \mu-\lambda^{2}\right) \theta c-\left(2 \theta \mu-\varphi \lambda^{2}\right) \gamma V_{2 R}^{\prime}}{\left[2(2-\varphi) \theta \mu-\lambda^{2}\right] \theta}, \\
A^{*}= & \frac{\left(D_{0}+\alpha r+\beta g\right) \lambda-c \theta \lambda-\lambda \gamma V_{2 R}^{\prime}}{2(2-\varphi) \theta \mu-\lambda^{2}}
\end{aligned}
$$

According to the structure of our model, a quadratic value function of the retailer can be assumed. Hence the current value function of the retailer can be set as follows:

$$
V_{R}(r, g)=x_{1} r+x_{2} r^{2}+x_{3} g+x_{4} g^{2}+x_{5} r g+x_{6} \text {. }
$$

What should be paid attention to is that, in our model framework, the retailer has no right to influence the goodwill of their product, for the reason that the goodwill only depends on the advertising investment of the manufacturer. We insert the partial differential of the two state variables and get the optimality in this situation as shown in Proposition 2.

Proposition 2. In the situation of the Stackelberg game consisting of a myopic manufacturer and a far-sighted retailer, the optimal retail price, wholesale price, and advertising investment can be expressed as follows:

$$
\begin{aligned}
p^{*}= & \frac{(1-\varphi)\left(D_{0}+\alpha r+\beta g\right)+\gamma\left(x_{1}+2 x_{2} r+x_{5} g\right)}{2(1-\varphi) \theta}+\frac{\left(D_{0}+\alpha r+\beta g\right) \lambda^{2}-c \theta \lambda^{2}-\lambda^{2} \gamma\left(x_{1}+2 x_{2} r+x_{5} g\right)}{4(2-\varphi) \theta^{2} \mu-2 \theta \lambda^{2}} \\
& +\frac{2(1-\varphi)^{2}\left(D_{0}+\alpha r+\beta g\right) \theta \mu+(1-\varphi)\left(2 \theta \mu-\lambda^{2}\right) \theta c-\left(2 \theta \mu-\varphi \lambda^{2}\right) \gamma\left(x_{1}+2 x_{2} r+x_{5} g\right)}{2(1-\varphi)\left[2(2-\varphi) \theta \mu-\lambda^{2}\right] \theta},
\end{aligned}
$$




$$
\begin{aligned}
& w^{*}=\frac{2(1-\varphi)^{2}\left(D_{0}+\alpha r+\beta g\right) \theta \mu+(1-\varphi)\left(2 \theta \mu-\lambda^{2}\right) \theta c-\left(2 \theta \mu-\varphi \lambda^{2}\right) \gamma\left(x_{1}+2 x_{2} r+x_{5} g\right)}{\left[2(2-\varphi) \theta \mu-\lambda^{2}\right] \theta}, \\
& A^{*}=\frac{\left(D_{0}+\alpha r+\beta g\right) \lambda-c \theta \lambda-\lambda \gamma\left(x_{1}+2 x_{2} r+x_{5} g\right)}{2(2-\varphi) \theta \mu-\lambda^{2}} .
\end{aligned}
$$

According to (19) we can know that there exist six Riccati formulas in it and they can be used to determine the exact coefficients in the current value function we assumed. These six Riccati formulas form a complex nonlinear equation system of six variables with various expressions which cannot be explained significantly. Therefore, the specific expressions of these solutions are omitted here owing to the limited space and they are available to the readers if requested. What should be paid attention to is that there is a specific condition to ensure the equation we assumed equaling to the expression of the retailer's real value function. This condition should meet the equation below:

$$
\lim _{t \rightarrow \infty} e^{-\rho t} V_{R}[g(t), r(t)]=0,
$$

where $[g(t), r(t)]$ can be calculated by inserting the optimality into the dynamic function of the goodwill and the reference price, and we get the time path of accumulated goodwill and reference price of the product as follows:

$$
\begin{aligned}
g(t)= & g_{\mathrm{ss}}+\left(g_{0}-g_{\mathrm{ss}}\right) e^{-\delta t}, \quad g(0)=g_{0}, \\
r(t)= & r_{\mathrm{ss}}+\left(r_{0}-r_{\mathrm{ss}}\right) e^{-\gamma t} \\
& +\frac{\sigma\left(g_{0}-g_{\mathrm{ss}}\right)}{\gamma-\delta}\left(e^{-\delta t}-e^{-\gamma t}\right), \quad r(0)=r_{0},
\end{aligned}
$$

where $\gamma \neq \delta$ and both of them are the real eigenvalues of the dynamic system matrix and $g_{\text {ss }}$ and $r_{\text {ss }}$ refer to the steady states of the goodwill and the reference price, respectively, given by $g_{\mathrm{ss}}=A^{*}, r_{\mathrm{ss}}=p^{*}+\sigma g_{\mathrm{ss}} / \gamma$. Then substituting the equilibriums above into the objective function of the manufacturer and the retailer in sequence, we can get their optimal profits as follows:

$$
\begin{aligned}
J_{M} & =\left[\varphi p^{*}+w^{*}-c\right]\left[D_{0}+\alpha r_{\mathrm{ss}}+\beta g_{\mathrm{ss}}-\theta p^{*}+\lambda A^{*}\right] \\
& -\frac{\mu}{2}\left(A^{*}\right)^{2}, \\
J_{R} & =\left(g_{0}-g_{\mathrm{ss}}\right)\left(x_{3}+2 x_{4} g_{\mathrm{ss}}+x_{5} r_{\mathrm{ss}}\right) \\
& +\left(r_{0}-r_{\mathrm{ss}}\right)\left(x_{1}+2 x_{2} r_{\mathrm{ss}}+x_{5} g_{\mathrm{ss}}\right) \\
& +\frac{\left[(1-\varphi) p^{*}-w^{*}\right]\left[D_{0}+\alpha r_{\mathrm{ss}}+\beta g_{\mathrm{ss}}-\theta p^{*}+\lambda A^{*}\right]}{\rho} .
\end{aligned}
$$

\section{Feedback Stackelberg Equilibrium of Far-Sighted Manufacturer}

5.1. Situation of Myopic Retailer. In this situation, we assume a supply chain consisting of a far-sighted manufacturer and a myopic retailer. The retailer is assumed myopic so that there is no constraint condition in her optimal programming model. The objective function of the retailer can be written as follows:

$$
\begin{aligned}
\max _{p(\cdot)}\{[(1-\varphi) p(t)-w(t)] \\
\left.\cdot\left[D_{0}+\alpha r(t)+\beta g(t)-\theta p(t)+\lambda A(t)\right]\right\} .
\end{aligned}
$$

However, a far-sighted manufacturer will take the dynamic relationships of reference price and goodwill into the consideration when she makes the decision. Hence the objective function of the manufacturer with $g(0)=g_{0} \geq$ $0, r(0)=r_{0} \geq 0$ can be written as follows:

$$
\begin{aligned}
\max _{w(\cdot), A(\cdot)} & \int_{0}^{\infty} e^{-\rho t}\left\{[\varphi p(t)+w(t)-c]\left[D_{0}+\alpha r(t)+\beta g(t)-\theta p(t)+\lambda A(t)\right]-\frac{\mu}{2} A^{2}(t)\right\} d t \\
\text { s.t. } & \dot{g}(t)=\delta[A(t)-g(t)], \\
& \dot{r}(t)=\gamma[p(t)-r(t)]+\sigma g(t) .
\end{aligned}
$$

The HJB equation of the far-sighted manufacturer with $r(t) \geq 0, g(t) \geq 0$ meets the equation below:

$$
\rho V_{M}=\max _{A \geq 0, w \geq 0}\{(\varphi p+w-c)
$$

$$
\begin{aligned}
& \cdot\left(D_{0}+\alpha r+\beta g-\theta p+\lambda A\right)-\frac{\mu}{2} A^{2} \\
& \left.+V_{1 M}^{\prime} \delta(A-g)+V_{2 M}^{\prime}[\gamma(p-r)+\sigma g]\right\} .
\end{aligned}
$$


Same as the calculation sequence above, the retail price of the retailer will be calculated first. In this situation, the manufacturer behaves farsightedly while the retailer is myopic. Hence, differentiate (24) with respect to the decision variable $p$ and equate it to zero; the retail price of the product can be expressed as follows:

$$
p^{*}=\frac{(1-\varphi)\left(D_{0}+\alpha r+\beta g+\lambda A\right)+\theta w}{2 \theta(1-\varphi)}
$$

Insert the optimal retail price into the objective function of the manufacturer and differentiate it with respect to the decision variable $w$ and equate it to zero (same as decision variable $A$ ); hence the wholesale price and the advertising investment can be expressed as follows:

$$
\begin{aligned}
& w^{*} \\
& =\frac{(1-\varphi)^{2}\left(D_{0}+\alpha r+\beta g+\lambda A\right)+(1-\varphi) c \theta+(1-\varphi) \gamma V_{2 M}^{\prime}}{(2-\varphi) \theta}, \\
& A^{*}=\frac{\left(D_{0}+\alpha r+\beta g\right) \varphi \lambda+(w-c) \theta \lambda+\lambda \gamma V_{2 M}^{\prime}+2 \theta \delta V_{1 M}^{\prime}}{2 \theta \mu-\varphi \lambda^{2}} .
\end{aligned}
$$

Then they will be taken into the expression of decision variable of the retailer. Therefore, the optimality in the situation of the Stackelberg game consisting of a far-sighted manufacturer and a myopic retailer can be expressed as follows:

$$
\begin{aligned}
p^{*} & =\frac{(1-\varphi)\left(D_{0}+\alpha r+\beta g\right)}{2(1-\varphi) \theta}+\frac{\left(D_{0}+\alpha r+\beta g\right) \lambda^{2}-c \theta \lambda^{2}+(3-2 \varphi) \lambda^{2} \gamma V_{2 M}^{\prime}+2(2-\varphi) \theta \delta \lambda V_{1 M}^{\prime}}{4(2-\varphi) \theta^{2} \mu-2 \theta \lambda^{2}} \\
& +\frac{(1-\varphi)\left[2 \theta \mu+(1-2 \varphi) \lambda^{2}\right] \gamma V_{2 M}^{\prime}+2(1-\varphi)^{2} \theta \delta \lambda V_{1 M}^{\prime}+2(1-\varphi)^{2}\left(D_{0}+\alpha r+\beta g\right) \theta \mu+(1-\varphi)\left(2 \theta \mu-\lambda^{2}\right) \theta c}{2(1-\varphi)\left[2(2-\varphi) \theta \mu-\lambda^{2}\right] \theta} \\
w^{*} & =\frac{2(1-\varphi)^{2}\left(D_{0}+\alpha r+\beta g\right) \theta \mu+(1-\varphi)\left(2 \theta \mu-\lambda^{2}\right) \theta c+(1-\varphi)\left[2 \theta \mu+(1-2 \varphi) \lambda^{2}\right] \gamma V_{2 M}^{\prime}+2(1-\varphi)^{2} \theta \delta \lambda V_{1 M}^{\prime}}{\left[2(2-\varphi) \theta \mu-\lambda^{2}\right] \theta} \\
A^{*} & =\frac{\left(D_{0}+\alpha r+\beta g\right) \lambda-c \theta \lambda+(3-2 \varphi) \lambda \gamma V_{2 M}^{\prime}+2(2-\varphi) \theta \delta V_{1 M}^{\prime}}{2(2-\varphi) \theta \mu-\lambda^{2}}
\end{aligned}
$$

According to the structure of our model, a quadratic value function of the manufacturer can be assumed. Hence the current value function of the manufacturer can be set as follows:

$$
V_{M}(r, g)=x_{7} r+x_{8} r^{2}+x_{9} g+x_{10} g^{2}+x_{11} r g+x_{12}
$$

We insert the partial differential of the two state variables and get the optimality in this situation as shown in Proposition 3 .

Proposition 3. In the situation of the Stackelberg game consisting of a far-sighted manufacturer and a myopic retailer, the optimal retail price, wholesale price, and advertising investment can be expressed as follows:

$$
\begin{aligned}
p^{*}= & \frac{(1-\varphi)\left(D_{0}+\alpha r+\beta g\right)}{2(1-\varphi) \theta}+\frac{2(1-\varphi)^{2}\left(D_{0}+\alpha r+\beta g\right) \theta \mu+(1-\varphi)\left(2 \theta \mu-\lambda^{2}\right) \theta c}{2(1-\varphi)\left[2(2-\varphi) \theta \mu-\lambda^{2}\right] \theta} \\
& +\frac{2(1-\varphi)^{2} \theta \delta \lambda\left(x_{9}+2 x_{10} g+x_{11} r\right)+(1-\varphi)\left[2 \theta \mu+(1-2 \varphi) \lambda^{2}\right] \gamma\left(x_{7}+2 x_{8} r+x_{11} g\right)}{2(1-\varphi)\left[2(2-\varphi) \theta \mu-\lambda^{2}\right] \theta} \\
& +\frac{\left(D_{0}+\alpha r+\beta g\right) \lambda^{2}-c \theta \lambda^{2}+(3-2 \varphi) \lambda^{2} \gamma\left(x_{7}+2 x_{8} r+x_{11} g\right)+2(2-\varphi) \theta \delta \lambda\left(x_{9}+2 x_{10} g+x_{11} r\right)}{4(2-\varphi) \theta^{2} \mu-2 \theta \lambda^{2}}, \\
w^{*}= & \frac{(1-\varphi)\left[2 \theta \mu+(1-2 \varphi) \lambda^{2}\right] \gamma\left(x_{7}+2 x_{8} r+x_{11} g\right)+2(1-\varphi)^{2} \theta \delta \lambda\left(x_{9}+2 x_{10} g+x_{11} r\right)}{\left[2(2-\varphi) \theta \mu-\lambda^{2}\right] \theta} \\
& +\frac{2(1-\varphi)^{2}\left(D_{0}+\alpha r+\beta g\right) \theta \mu+(1-\varphi)\left(2 \theta \mu-\lambda^{2}\right) \theta c}{2\left(2-\lambda^{2}\right] \theta}, \\
A^{*}= & \frac{\left(D_{0}+\alpha r+\beta g\right) \lambda-c \theta \lambda+(3-2 \varphi) \lambda \gamma\left(x_{7}+2 x_{8} r+x_{11} g\right)+2(2-\varphi) \theta \delta\left(x_{9}+2 x_{10} g+x_{11} r\right)}{2(2-\varphi) \theta \mu-\lambda^{2}} .
\end{aligned}
$$


According to (30) we can know that there exist six Riccati formulas in it and they can be used to determine the exact coefficients in the current value function we assumed. These six Riccati formulas form a complex nonlinear equation system of six variables with various expressions which cannot be explained significantly. Therefore, the specific expressions of these solutions are omitted here owing to the limited space and they are available to the readers if requested. What should be paid attention to is that there is a specific condition to ensure the equation we assumed equaling to the expression of the manufacturer's real value function. This condition should meet the equation below:

$$
\lim _{t \rightarrow \infty} e^{-\rho t} V_{M}[g(t), r(t)]=0,
$$

where $[g(t), r(t)]$ can be calculated by inserting the optimality into the dynamic function of the goodwill and the reference price, and we get the time path of accumulated goodwill and reference price of products as follows:

$$
\begin{aligned}
g(t)= & g_{\mathrm{ss}}+\left(g_{0}-g_{\mathrm{ss}}\right) e^{-\delta t}, \quad g(0)=g_{0}, \\
r(t)= & r_{\mathrm{ss}}+\left(r_{0}-r_{\mathrm{ss}}\right) e^{-\gamma t} \\
& +\frac{\sigma\left(g_{0}-g_{\mathrm{ss}}\right)}{\gamma-\delta}\left(e^{-\delta t}-e^{-\gamma t}\right), \quad r(0)=r_{0},
\end{aligned}
$$

where $\gamma \neq \delta$ and both of them are the real eigenvalues of the dynamic system matrix and $g_{\mathrm{ss}}$ and $r_{\mathrm{ss}}$ refer to the steady states of the goodwill and the reference price, respectively, given by $g_{\mathrm{ss}}=A^{*}, r_{\mathrm{ss}}=p^{*}+\sigma g_{\mathrm{ss}} / \gamma$. Then substituting the equilibriums above into the objective function of the manufacturer and the retailer in sequence, we can get their optimal profits as follows:

$$
\begin{aligned}
J_{M} & =\left(g_{0}-g_{\mathrm{ss}}\right)\left(x_{9}+2 x_{10} g_{\mathrm{ss}}+x_{11} r_{\mathrm{ss}}\right)+\left(r_{0}-r_{\mathrm{ss}}\right) \\
& \cdot\left(x_{7}+2 x_{8} r_{\mathrm{ss}}+x_{11} g_{\mathrm{ss}}\right) \\
& +\frac{\left(\varphi p^{*}+w^{*}-c\right)\left[D_{0}+\alpha r_{\mathrm{ss}}+\beta g_{\mathrm{ss}}-\theta p^{*}+\lambda A^{*}\right]}{\rho} \\
& -\frac{\mu}{2 \rho}\left(A^{*}\right)^{2}, \\
J_{R} & =\left[(1-\varphi) p^{*}-w^{*}\right] \\
& \cdot\left(D_{0}+\alpha r_{\mathrm{ss}}+\beta g_{\mathrm{ss}}-\theta p^{*}+\lambda A^{*}\right) .
\end{aligned}
$$

5.2. Situation of Far-Sighted Retailer. In this situation, both the manufacturer and the retailer are far-sighted; they seek for the profit maximization in the long run considering the effects of the reference price and the goodwill at the same time. Therefore, there will be constraint conditions for this optimal programming model. When taking the dynamic relationships and the objective functions together, we develop a differential game model considering the marketing-operation relationship with $g(0)=g_{0} \geq 0, r(0)=r_{0} \geq 0$ as follows:

$$
\begin{aligned}
\max _{w(\cdot), A(\cdot)} & \int_{0}^{\infty} e^{-\rho t}\left\{[\varphi p(t)+w(t)-c]\left[D_{0}+\alpha r(t)+\beta g(t)-\theta p(t)+\lambda A(t)\right]-\frac{\mu}{2} A^{2}(t)\right\} d t, \\
\max _{p(\cdot)} & \int_{0}^{\infty} e^{-\rho t}\left\{[(1-\varphi) p(t)-w(t)]\left[D_{0}+\alpha r(t)+\beta g(t)-\theta p(t)+\lambda A(t)\right]\right\} d t \\
\text { s.t. } & \dot{g}(t)=\delta[A(t)-g(t)], \\
& \dot{r}(t)=\gamma[p(t)-r(t)]+\sigma g(t) .
\end{aligned}
$$

The HJB function of the manufacturer and the retailer with $r(t) \geq 0, g(t) \geq 0$ can be written as follows:

$$
\begin{aligned}
& \rho V_{M}=\max _{A \geq 0, w \geq 0}\{(\varphi p+w-c) \\
& \cdot\left(D_{0}+\alpha r+\beta g-\theta p+\lambda A\right)-\frac{\mu}{2} A^{2} \\
& \left.+V_{1 M}^{\prime} \delta(A-g)+V_{2 M}^{\prime}[\gamma(p-r)+\sigma g]\right\}, \\
& \rho V_{R}=\max _{p \geq 0}\{[(1-\varphi) p-w] \\
& \cdot\left(D_{0}+\alpha r+\beta g-\theta p+\lambda A\right)+V_{1 R}^{\prime} \delta(A-g) \\
& \left.+V_{2 R}^{\prime}[\gamma(p-r)+\sigma g]\right\} .
\end{aligned}
$$

Same as the calculation sequence above, the retail price of the retailer will be calculated first. In this situation, both of the retailer and manufacturer behave farsightedly. Hence, differentiate (36) with respect to the decision variable $p$ and equate it to zero; the retail price of the product can be expressed as

$$
p^{*}=\frac{(1-\varphi)\left(D_{0}+\alpha r+\beta g+\lambda A\right)+\theta w+\gamma V_{2 R}^{\prime}}{2 \theta(1-\varphi)} .
$$

Insert the optimal retail price into the objective function of the manufacturer and differentiate it with respect to the decision variable $w$ and equate it to zero (same as decision variable $A$ ); hence, the wholesale price and the advertising investment can be expressed as follows: 


$$
\begin{aligned}
& w^{*}=\frac{(1-\varphi)^{2}\left(D_{0}+\alpha r+\beta g+\lambda A\right)+(1-\varphi) c \theta+(1-\varphi) \gamma V_{2 M}^{\prime}-\gamma V_{2 R}^{\prime}}{(2-\varphi) \theta}, \\
& A^{*}=\frac{\left(D_{0}+\alpha r+\beta g\right) \varphi \lambda+(w-c) \theta \lambda+\lambda \gamma V_{2 M}^{\prime}+2 \theta \delta V_{1 M}^{\prime}}{2 \theta \mu-\varphi \lambda^{2}} .
\end{aligned}
$$

Then they will be taken into the expression of decision variable of the retailer. Therefore, the optimality in the situation of the Stackelberg game consisting of a far-sighted manufacturer and a far-sighted retailer can be expressed as follows:

$$
\begin{aligned}
p^{*} & =\frac{(1-\varphi)\left(D_{0}+\alpha r+\beta g\right)+\gamma V_{2 R}^{\prime}}{2(1-\varphi) \theta}+\frac{\left(D_{0}+\alpha r+\beta g\right) \lambda^{2}-c \theta \lambda^{2}+(3-2 \varphi) \lambda^{2} \gamma V_{2 M}^{\prime}+2(2-\varphi) \theta \delta \lambda V_{1 M}^{\prime}-\lambda^{2} \gamma V_{2 R}^{\prime}}{4(2-\varphi) \theta^{2} \mu-2 \theta \lambda^{2}} \\
& +\frac{(1-\varphi)\left[2 \theta \mu+(1-2 \varphi) \lambda^{2}\right] \gamma V_{2 M}^{\prime}+2(1-\varphi)^{2} \theta \delta \lambda V_{1 M}^{\prime}-\left(2 \theta \mu-\varphi \lambda^{2}\right) \gamma V_{2 R}^{\prime}+2(1-\varphi)^{2}\left(D_{0}+\alpha r+\beta g\right) \theta \mu+(1-\varphi)\left(2 \theta \mu-\lambda^{2}\right) \theta c}{2(1-\varphi)\left[2(2-\varphi) \theta \mu-\lambda^{2}\right] \theta}, \\
w^{*} & \\
& =\frac{2(1-\varphi)^{2}\left(D_{0}+\alpha r+\beta g\right) \theta \mu+(1-\varphi)\left(2 \theta \mu-\lambda^{2}\right) \theta c+(1-\varphi)\left[2 \theta \mu+(1-2 \varphi) \lambda^{2}\right] \gamma V_{2 M}^{\prime}+2(1-\varphi)^{2} \theta \delta \lambda V_{1 M}^{\prime}-\left(2 \theta \mu-\varphi \lambda^{2}\right) \gamma V_{2 R}^{\prime}}{\left[2(2-\varphi) \theta \mu-\lambda^{2}\right] \theta}, \\
A^{*} & =\frac{\left(D_{0}+\alpha r+\beta g\right) \lambda-c \theta \lambda+(3-2 \varphi) \lambda \gamma V_{2 M}^{\prime}+2(2-\varphi) \theta \delta V_{1 M}^{\prime}-\lambda \gamma V_{2 R}^{\prime}}{2(2-\varphi) \theta \mu-\lambda^{2}} .
\end{aligned}
$$

According to the structure of our model, a quadratic value function of the retailer and the manufacturer can be assumed. Hence, the current value function of the retailer and the manufacturer can be set as follows:

$$
\begin{aligned}
& V_{R}(r, g)=y_{1} r+y_{2} r^{2}+y_{3} g+y_{4} g^{2}+y_{5} r g+y_{6}, \\
& V_{M}(r, g)=y_{7} r+y_{8} r^{2}+y_{9} g+y_{10} g^{2}+y_{11} r g+y_{12} .
\end{aligned}
$$

What should be paid attention to is that, in our model framework, the retailer has no right to influence the goodwill of their product, for the reason that the goodwill only depends on the advertising investment of the manufacturer. We insert the partial differential of the two state variables and get the optimality in this situation as shown in Proposition 4.

Proposition 4. In the situation of the Stackelberg game consisting of a far-sighted manufacturer and a far-sighted retailer, the optimal retail price, wholesale price, and advertising investment can be expressed as follows:

$$
\begin{aligned}
p^{*} & =\frac{(1-\varphi)\left(D_{0}+\alpha r+\beta g\right)+\gamma\left(y_{1}+2 y_{2} r+y_{5} g\right)}{2(1-\varphi) \theta}+\frac{2(1-\varphi)^{2}\left(D_{0}+\alpha r+\beta g\right) \theta \mu+(1-\varphi)\left(2 \theta \mu-\lambda^{2}\right) \theta c}{2(1-\varphi)\left[2(2-\varphi) \theta \mu-\lambda^{2}\right] \theta} \\
& +\frac{(1-\varphi)\left[2 \theta \mu+(1-2 \varphi) \lambda^{2}\right] \gamma\left(y_{7}+2 y_{8} r+y_{11} g\right)+2(1-\varphi)^{2} \theta \delta \lambda\left(y_{9}+2 y_{10} g+y_{11} r\right)-\left(2 \theta \mu-\varphi \lambda^{2}\right) \gamma\left(y_{1}+2 y_{2} r+y_{5} g\right)}{2(1-\varphi)\left[2(2-\varphi) \theta \mu-\lambda^{2}\right] \theta} \\
& +\frac{\left(D_{0}+\alpha r+\beta g\right) \lambda^{2}-c \theta \lambda^{2}+(3-2 \varphi) \lambda^{2} \gamma\left(y_{7}+2 y_{8} r+y_{11} g\right)+2(2-\varphi) \theta \delta \lambda\left(y_{9}+2 y_{10} g+y_{11} r\right)-\lambda^{2} \gamma\left(y_{1}+2 y_{2} r+y_{5} g\right)}{4(2-\varphi) \theta^{2} \mu-2 \theta \lambda^{2}}, \\
w^{*} & =\frac{2(1-\varphi)^{2}\left(D_{0}+\alpha r+\beta g\right) \theta \mu+(1-\varphi)\left(2 \theta \mu-\lambda^{2}\right) \theta c+(1-\varphi)\left[2 \theta \mu+(1-2 \varphi) \lambda^{2}\right] \gamma\left(y_{7}+2 y_{8} r+y_{11} g\right)}{\left[2(2-\varphi) \theta \mu-\lambda^{2}\right] \theta} \\
& +\frac{2(1-\varphi)^{2} \theta \delta \lambda\left(y_{9}+2 y_{10} g+y_{11} r\right)-\left(2 \theta \mu-\varphi \lambda^{2}\right) \gamma\left(y_{1}+2 y_{2} r+y_{5} g\right)}{\left[2(2-\varphi) \theta \mu-\lambda^{2}\right] \theta}, \\
A^{*} & \frac{\left(D_{0}+\alpha r+\beta g\right) \lambda-c \theta \lambda+(3-2 \varphi) \lambda \gamma\left(y_{7}+2 y_{8} r+y_{11} g\right)+2(2-\varphi) \theta \delta\left(y_{9}+2 y_{10} g+y_{11} r\right)-\lambda \gamma\left(y_{1}+2 y_{2} r+y_{5} g\right)}{2(2-\varphi) \theta \mu-\lambda^{2}} .
\end{aligned}
$$


According to (40) we can know that there exist twelve Riccati formulas in it and they can be used to determine the exact coefficients in the current value functions we assumed. These twelve Riccati formulas form a complex nonlinear equation system of twelve variables with various expressions which cannot be explained significantly. Therefore, the specific expressions of these solutions are omitted here owing to the limited space and they are available to the readers if requested. What should be paid attention to is that there are specific conditions to ensure the equations we assumed equaling to the expressions of the real value functions of the manufacturer and the retailer. These conditions should meet the equations below:

$$
\begin{aligned}
& \lim _{t \rightarrow \infty} e^{-\rho t} V_{R}[g(t), r(t)]=0, \\
& \lim _{t \rightarrow \infty} e^{-\rho t} V_{M}[g(t), r(t)]=0,
\end{aligned}
$$

where $[g(t), r(t)]$ can be calculated by inserting the optimality into the dynamic function of the goodwill and the reference price, and we get the time path of accumulated goodwill and reference price of products as follows:

$$
\begin{aligned}
g(t)= & g_{\mathrm{ss}}+\left(g_{0}-g_{\mathrm{ss}}\right) e^{-\delta t}, \quad g(0)=g_{0}, \\
r(t)= & r_{\mathrm{ss}}+\left(r_{0}-r_{\mathrm{ss}}\right) e^{-\gamma t} \\
& +\frac{\sigma\left(g_{0}-g_{\mathrm{ss}}\right)}{\gamma-\delta}\left(e^{-\delta t}-e^{-\gamma t}\right), \quad r(0)=r_{0},
\end{aligned}
$$

where $\gamma \neq \delta$ and both of them are the real eigenvalues of the dynamic system matrix and $g_{\mathrm{ss}}$ and $r_{\mathrm{ss}}$ refer to the steady states of the goodwill and the reference price, respectively, given by $g_{\mathrm{ss}}=A^{*}, r_{\mathrm{ss}}=p^{*}+\sigma g_{\mathrm{ss}} / \gamma$. Then substituting the equilibriums above into the objective function of the manufacturer and the retailer in sequence, we can get their optimal profits as follows:

$$
\begin{aligned}
J_{M} & =\left(g_{0}-g_{\mathrm{ss}}\right)\left(y_{9}+2 y_{10} g_{\mathrm{ss}}+y_{11} r_{\mathrm{ss}}\right) \\
& +\left(r_{0}-r_{\mathrm{ss}}\right)\left(y_{7}+2 y_{8} r_{\mathrm{ss}}+y_{11} g_{\mathrm{ss}}\right) \\
& +\frac{\left(\varphi p^{*}+w^{*}-c\right)\left[D_{0}+\alpha r_{\mathrm{ss}}+\beta g_{\mathrm{ss}}-\theta p^{*}+\lambda A^{*}\right]}{\rho} \\
& -\frac{\mu}{2 \rho}\left(A^{*}\right)^{2}, \\
J_{R} & =\left(g_{0}-g_{\mathrm{ss}}\right)\left(y_{3}+2 y_{4} g_{\mathrm{ss}}+y_{5} r_{\mathrm{ss}}\right) \\
& +\left(r_{0}-r_{\mathrm{ss}}\right)\left(y_{1}+2 y_{2} r_{\mathrm{ss}}+y_{5} g_{\mathrm{ss}}\right) \\
& +\frac{\left[(1-\varphi) p^{*}-w^{*}\right]\left[D_{0}+\alpha r_{\mathrm{ss}}+\beta g_{\mathrm{ss}}-\theta p^{*}+\lambda A^{*}\right]}{\rho} .
\end{aligned}
$$

\section{Comparison between Situations}

In this section, we mainly pay attention to the strategies difference and sensitivity analyses in the four situations analyzed above. Such kind of comparison will be conducted through the form of numerical analyses for the reason that although the analytical solutions can be worked out by our models, these analytical expressions will be too complex to analyze. Considering the disadvantage of the analytical treatment, we tend to use the numerical treatment to explore more insight of equilibriums instead. Because the basic model framework is assumed to be dynamic with time, all the equilibriums can be varied with time too. To avoid the influence of the time, we extend the planning horizon to infinite so that the strategies in this section refer to the strategies in the steady state. Overall, it is our interest to study two kinds of strategies of the manufacturer and the retailer, namely, the pricing strategy and the behavior choice.

6.1. Pricing Strategies between Situations. In this section, we examine the pricing strategies of the manufacturer and the retailer in both the far-sighted and myopic situations. As the manufacturer plays the role of leader in the supply chain, the retailer just acts as the follower and makes the decision of the retail price after observing the action of the manufacturer. As previously analyzed, the retailer's reaction functions in the myopic and far-sighted situations are given as follows, respectively:

$$
\begin{aligned}
p^{* m} & =\frac{(1-\varphi)\left(D_{0}+\alpha r+\beta g+\lambda A\right)+\theta w}{2 \theta(1-\varphi)}, \\
p^{* f} & =\frac{(1-\varphi)\left(D_{0}+\alpha r+\beta g+\lambda A\right)+\theta w+\gamma V_{2 R}^{\prime}}{2 \theta(1-\varphi)},
\end{aligned}
$$

where the superscript $m$ refers to the myopic situation and $f$ refers to the far-sighted situation. From (45) we can know that, for a myopic retailer, although she ignores the dynamics of the goodwill and the reference price, her retail pricing strategy still depends on the state variables including $r$ and $g$. Comparing these two optimal retail price functions, we can get Proposition 5.

Proposition 5. Compared with the far-sighted retailer, the myopic retailer tends to ignore the marginal value of the state variable, that is, the reference price effect.

For this proposition, as the analytical expressions are too complex to analyze, we tend to use the numerical treatment to explore more insight of equilibriums instead. To be consistent with the previous studies, the specific values of the parameters in our numerical analysis can be set as follows:

$$
\begin{aligned}
& \text { Demand parameter: } D_{0}=1, \varepsilon=1, \alpha=0.7, \beta= \\
& 0.6, \lambda=0.4 \\
& \text { Cost parameter: } c=0, \mu=1 \\
& \text { Perceived goodwill parameter: } \delta=0.8 \\
& \text { Reference price parameter: } \gamma=0.7, \sigma=0.5 \\
& \text { Discount rate: } \rho=0.1
\end{aligned}
$$

As our goal is to study the effects of the myopic and far-sighted behaviors on the advertising investment and the pricing strategies of the participating members in the supply chain, the parameters including $\alpha, \beta, \lambda$ are relatively 
important in our analysis. Therefore, the values of these parameters are assumed lying in $[0,1]$ with the interval of 0.05 . We examined different combinations of these values and the relative effects on the strategies. In our model, there are two expressions to depict $x_{2}$; one is positive while the other one is negative. The stability condition for the steady state is only satisfied with the positive expression of $x_{2}$. If the other expression is chosen, the stability condition will never be satisfied. The choices of other multiexpression parameters also follow the same rule as $x_{2}$ in this situation. Considering that it is difficult to verify the results in our numerical analyses analytically, the relative results stated in our paper will be expressed in the form of claims as follows.

Claim 1. For all admissible parameter values, when cooperated with a myopic manufacturer, a myopic retailer charges a lower steady state retail price than the price the far-sighted retailer charges; that is, $p_{\mathrm{ss}}^{m}<p_{\mathrm{ss}}^{f}$. However, when cooperated with a far-sighted manufacturer, a myopic retailer charges a higher steady state retail price than the price the farsighted retailer charges; that is, $p_{s s}^{m}>p_{s s}^{f}$.

According to Proposition 5, no matter what kind of the behavior choice the manufacturer makes, the myopic retailer ignores the effect of reference price. However, such kind of the reference price effect differs according to the behavior choice of the manufacturer. It is mainly because the behavior choice of the manufacturer is also related to the reference price through the mediating variable goodwill. Therefore, in our numerical analysis, the pricing strategy of the retailer differs a lot when she meets different kind of the manufacturer. When the manufacturer is myopic, she ignores both the goodwill and reference price effects, which leads to a positive $V_{2 R}^{\prime}$, while when the manufacturer is far-sighted, she takes both the goodwill and reference price effects into consideration, which leads to a negative $V_{2 R}^{\prime}$. In other words, consumers will spend more money on the products when they face a supply chain consisting of two different behavioral types of the participating members.

According to the relationship between the reference price at the beginning and that in the steady state, that is, $r_{0}$ and $r_{\mathrm{ss}}$, there exist two kinds of pricing strategies including skimming pricing strategy and penetration pricing strategy for the retailer. When $r_{0}<r_{\text {ss }}$, it is indicated from the numerical analysis that the control paths will decrease as time goes by. It is better for the retailer to take skimming pricing strategy in this situation. However, when $r_{0}>r_{\text {ss }}$, it is indicated from the numerical analysis that the control paths will increase as time goes by. Therefore, it is better for the retailer to take penetration pricing strategy in this situation.

Claim 2. For all admissible parameter values, a far-sighted manufacturer invests more on advertising and charges a higher wholesale price. Furthermore, a certain behavioral manufacturer invests more on advertising when she faces a myopic retailer (i.e., $A_{\mathrm{ss}}^{m}>A_{\mathrm{ss}}^{f}$ ) and charges a higher wholesale price to a myopic retailer than a far-sighted retailer (i.e., $\left.w_{\mathrm{ss}}^{m}>w_{\mathrm{ss}}^{f}\right)$.
Generally speaking, a far-sighted manufacturer considers the effects of the goodwill and the reference price, so she tends to invest more in the advertisement to increase the goodwill and charges a higher wholesale price no matter what kind of the retailer she meets. Furthermore, when we pay attention to the decisions of a certain manufacturer, the steady level of advertising investment and wholesale price will be different according to the behavior choice of the retailer she cooperates with. In other words, when the manufacturer faces a myopic retailer, she will invest more in the advertisement and sell the products at a higher wholesale price; on the contrary, when she faces a far-sighted retailer, the products will be sold at a lower wholesale price with a lower level of the advertisement.

Claim 3. For all admissible parameter values, the total profits of the supply chain consisting of a far-sighted manufacturer and a myopic retailer rank first in the four different combinations, while the supply chain consisting of a myopic manufacturer and a far-sighted retailer earns the lowest profit.

It is interesting that Claim 3 provides a different view of the combination. When the consumers are sensitive to the price, the market demand will decrease sharply with the increasing price. Hence the combination of a myopic retailer and a far-sighted manufacturer will lead to a higher retail price, wholesale price, and advertising investment level than that in the situation of both far-sighted participating members. In other words, the consumers will be influenced by the advertisement and buy the products at a higher price.

6.2. Sensitivity Analysis. In this subsection, we conduct the sensitivity analysis to compare the profit of the manufacturer with the profit of the retailer in the four game situations analyzed above. To understand the influence of different market demand structures on the final profits of the participating members and the whole supply chain, we focus on the parameters $\alpha, \beta, \lambda$. Also, to better analyze the revenue sharing influence on the strategies of the manufacturer and the retailer, we conduct the sensitivity analysis of the revenue sharing parameter $\varphi$. The relative claims are as follows.

Claim 4. For all admissible parameter values, compared with the corresponding situations, the total profits of the whole supply chain increase with the increasement of parameter $\alpha$. And both of the profits of the manufacturer and the retailer increase in all the four situations with a lower retail price and wholesale price.

A higher parameter $\alpha$ shows a higher marginal effect of the reference price on the market demand. In this way, the consumers are much more sensitive to the reference price, which means that a higher reference price will lead to a much higher market demand.

Claim 5. For all admissible parameter values, compared with the corresponding situations, the total profits of the supply chain increase with the increasement of parameter $\beta$, especially in the situation of the far-sighted manufacturer. 
A higher parameter $\beta$ shows a higher marginal effect of the goodwill on the market demand. In this way, the consumers are much more sensitive to the goodwill of the product, which means that the higher the goodwill is, the higher the demand will be. What is more, we notice that the profits of the manufacturer and the retailer increase sharply in the situation of the far-sighted manufacturer, which are all up by more than $100 \%$. It is mainly because when the manufacturer is far-sighted, she takes the effect of the accumulated goodwill into consideration and invests much more on the advertisement to increase the goodwill of the product. Such kind of the increasing investment will lead to a multiplier effect on the market demand. Hence, the final increment of the profits will be more than $100 \%$.

Claim 6. For all admissible parameter values, compared with the corresponding situations, the total profits of the supply chain increase with the increasement of parameter $\lambda$, especially in the situation of the far-sighted manufacturer.

As we have mentioned earlier, in our model we assume that even a myopic manufacturer will invest in the advertisement for the reason that the advertisement has the effect to improve the market demand instantaneously, although in the view of the myopic manufacturer such advertising investment has no effect on the goodwill in the long run. Therefore, an increasing $\lambda$ means a higher marginal effect of the advertising investment on the market demand. No matter what kind of behavior the manufacturer chooses, her profit will increase. And when the manufacturer is far-sighted, her profit will increase sharply.

Claim 7. For all admissible parameter values, compared with the corresponding situations, the total profits of the supply chain increase with the increasement of revenue sharing parameter $\varphi$. Thereinto, the profits of the manufacturer increase in all the four situations. However, the profits of the retailer decrease in the first three situations.

As clarified in Claim 7, it seems strange that the profit of the far-sighted retailer increases with the increasement of the revenue sharing parameter. For this situation, both the manufacturer and the retailer are far-sighted; they make decisions considering the effects of the goodwill and the reference price on the market demand. Although there are more revenues shared with the manufacturer, the retailer still can be beneficial due to the increasement of the total market demand. Furthermore, we also notice that both the retail price and the wholesale price decrease with the increasement of $\varphi$, while the advertising investment of the manufacturer increases in all the four situations. Hence, the steady state of the goodwill increases a lot with a higher revenue sharing proportion.

\section{Conclusions}

Based on the background of dynamic environment, participating members in the supply chain should act as farsighted decision-makers for a better long-term performance.
However, most of the managers prefer the myopic decisions in practice. This kind of myopic/far-sighted behavior has a significant influence on dynamic supply chain coordination. Therefore, this paper formulates the differential game models to further study the effects of such behavior choice (myopic or far-sighted) on the advertising investment through reference price effect in the dynamic supply chain. The differential game theory is introduced here to solve this dynamic problem. Considering that the different game structures may lead to different results, the equilibrium wholesale price, the investment on advertising, and the retail price are analyzed in the Stackelberg game, respectively, with the different combinations of the far-sighted and myopic behaviors of the participating members in the supply chain.

The main conclusions of this article include the following: (i) since the advertisement affects the consumers' behavior significantly, the participating members in the supply chain should invest more in advertising to improve the goodwill and the relative reference price reflected in the minds of consumers, and in this way the demand and profit will increase; (ii) when the participating members are myopic, they ignore the effects of the reference price and the perceived goodwill in the minds of consumers. For the manufacturer, a far-sighted one will invest more in the advertisement and charge a higher wholesale price regardless of the behavior choice of the retailer. However, such kind of the ignorance leads to different results on the retail pricing strategies of the retailer. The far-sighted retailer will charge a lower retail price when she faces a far-sighted manufacturer and charge higher when she cooperates with a myopic manufacturer; (iii) a farsighted manufacturer will invest more in the advertisement, in which the manufacturer invests most when she cooperates with a myopic retailer. In this paper, we only consider the situation of the supply chain consisting of one manufacturer and one retailer, which could be expanded to multimembers to study a more practical phenomenon and other interesting problems. On the other hand, the strategies in these situations are assumed stationary. There exist more common situations that the strategies of the player can be varied with time. Such extensions are left for future research.

\section{Notations}

\section{Decision Variables of Manufacturer and Retailer}

$A(t)$ : Advertising investment of the manufacturer

$w(t)$ : Wholesale price of the manufacturer

$p(t)$ : Retail price of the retailer.

\section{Parameters and Other Variables}

$\mu$ : Cost parameter associated with the advertising investment of manufacturer, $\mu>0$

$\delta$ : Coefficient associated with the advertising investment and the decay rate of goodwill in the function of goodwill, $\delta>0$ 


\begin{tabular}{|c|c|}
\hline$\gamma, \sigma:$ & $\begin{array}{l}\text { Coefficient associated with the difference } \\
\text { between market price and reference price } \\
\text { and the goodwill in the function of } \\
\text { reference price, } \gamma, \sigma>0\end{array}$ \\
\hline$\alpha, \beta:$ & $\begin{array}{l}\text { Coefficient associated with the difference } \\
\text { between reference price and market price } \\
\text { and the goodwill in the demand function, } \\
\alpha, \beta>0\end{array}$ \\
\hline$\varepsilon:$ & $\begin{array}{l}\text { Coefficient associated with the effect of } \\
\text { retail price on current demand, } \varepsilon>0\end{array}$ \\
\hline$\lambda:$ & $\begin{array}{l}\text { Coefficient associated with the } \\
\text { instantaneous effect of the advertisement } \\
\text { on current demand, } \lambda>0\end{array}$ \\
\hline$\rho:$ & Discount rate \\
\hline$c:$ & $\begin{array}{l}\text { Marginal production cost independent of } \\
\text { the advertising investment of the } \\
\text { manufacturer }\end{array}$ \\
\hline$D(t):$ & $\begin{array}{l}\text { Demand for the product at time } t \text {, with } \\
\text { initial demand } D_{0} \geq 0\end{array}$ \\
\hline$w(t):$ & $\begin{array}{l}\text { Wholesale price at time } t \text {, with } \\
w(0)=w_{0} \geq 0 \text {, controlled by the } \\
\text { manufacturer }\end{array}$ \\
\hline$p(t):$ & $\begin{array}{l}\text { Retail price at time } t \text {, with } p(0)=p_{0} \geq 0 \text {, } \\
\text { controlled by the retailer }\end{array}$ \\
\hline$g(t), r(t):$ & $\begin{array}{l}\text { Goodwill and reference price at time } t \text {, } \\
\text { with } g(0)=g_{0} \geq 0, r(0)=r_{0} \geq 0\end{array}$ \\
\hline$J_{M}, J_{1}$ & $\begin{array}{l}\text { Objective function (which is expressed as } \\
\text { net profit) of the manufacturer, retailer, } \\
\text { and the whole supply chain for } t \in[0, \infty) \text {. }\end{array}$ \\
\hline
\end{tabular}

\section{Conflicts of Interest}

The authors declare that there are no conflicts of interest regarding the publication of this paper.

\section{Acknowledgments}

This work was supported by the National Natural Science Foundation of China (Project no. 71272111).

\section{References}

[1] D. Chakravarti, A. Mitchell, and R. Staelin, "Judgment based marketing decision models: an experimental investigation of the decision calculus approach," Management Science, vol. 25, no. 3, pp. 251-263, 1979.

[2] J. R. Hauser, D. I. Simester, and B. Wernerfelt, "Customer satisfaction incentives," Marketing Science, vol. 13, no. 4, pp. 327350, 1994.

[3] G. Liu, S. P. Sethi, and J. Zhang, "Myopic vs. far-sighted behaviours in a revenue-sharing supply chain with reference quality effects," International Journal of Production Research, vol. 54, no. 5, pp. 1334-1357, 2016.

[4] S. Jørgensen, S. Taboubi, and G. Zaccour, "Retail promotions with negative brand image effects: is cooperation possible?" European Journal of Operational Research, vol. 150, no. 2, pp. 395-405, 2003.

[5] H. Benchekroun, G. Martín-Herrán, and S. Taboubi, "Could myopic pricing be a strategic choice in marketing channels?
A game theoretic analysis," Journal of Economic Dynamics \& Control, vol. 33, no. 9, pp. 1699-1718, 2009.

[6] G. Fibich, A. Gavious, and O. Lowengart, "Explicit solutions of optimization models and differential games with nonsmooth (asymmetric) reference-price effects," Operations Research, vol. 51, no. 5, pp. 721-734, 2003.

[7] J. Zhang, Q. Gou, L. Liang, and Z. Huang, "Supply chain coordination through cooperative advertising with reference price effect," Omega, vol. 41, no. 2, pp. 345-353, 2013.

[8] R. Dorfman and P. O. Steiner, "Optimal advertising and optimal quality," The American Economic Review, vol. 44, no. 5, pp. 826836, 1954.

[9] I. Chioveanu, "Advertising, brand loyalty and pricing," Games and Economic Behavior, vol. 64, no. 1, pp. 68-80, 2008.

[10] X.-L. He, A. Prasad, and S. P. Sethi, "Cooperative advertising and pricing in a dynamic stochastic supply chain: feedback stackelberg strategies," Production and Operations Management, vol. 18, no. 1, pp. 78-94, 2009.

[11] J. Xie and J. C. Wei, "Coordinating advertising and pricing in a manufacturer-retailer channel," European Journal of Operational Research, vol. 197, no. 2, pp. 785-791, 2009.

[12] J. Chaab and M. Rasti-Barzoki, "Cooperative advertising and pricing in a manufacturer-retailer supply chain with a general demand function; a game-theoretic approach," Computers \& Industrial Engineering, vol. 99, pp. 112-123, 2016.

[13] S. Karray and S. H. Amin, "Cooperative advertising in a supply chain with retail competition," International Journal of Production Research, vol. 53, no. 1, pp. 88-105, 2015.

[14] L. Feng, J. Zhang, and W. Tang, "A joint dynamic pricing and advertising model of perishable products," Journal of the Operational Research Society, vol. 66, no. 8, pp. 1341-1351, 2015.

[15] J. M. Lattin and R. E. Bucklin, "Reference Effects of Price and Promotion on Brand Choice Behavior," Marketing Research, vol. 26, no. 3, pp. 299-310, 1989.

[16] I. Popescu and Y. Wu, "Dynamic pricing strategies with reference effects," Operations Research, vol. 55, no. 3, pp. 413-429, 2007.

[17] Q. Geng, C. Wu, and K. Li, "Pricing and promotion frequency in the presence of reference price effects in supply chains," California Journal of Operations Management, vol. 8, no. 1, pp. 74-82, 2010.

[18] G. Fibich, A. Gavious, and O. Lowengart, "Optimal price promotion in the presence of asymmetric reference-price effects," Managerial and Decision Economics, vol. 28, no. 6, pp. 569-577, 2007.

[19] J. Nasiry and I. Popescu, "Dynamic pricing with loss-averse consumers and peak-end anchoring," Operations Research, vol. 59, no. 6, pp. 1361-1368, 2011.

[20] J. Zhang, W.-Y. Kevin Chiang, and L. Liang, "Strategic pricing with reference effects in a competitive supply chain," Omega (United Kingdom), vol. 44, no. 2, pp. 126-135, 2014.

[21] G. Martín-Herrán, S. Taboubi, and G. Zaccour, "Dual role of price and myopia in a marketing channel," European Journal of Operational Research, vol. 219, no. 2, pp. 284-295, 2012.

[22] G. Martín-Herrán and S. Taboubi, "Price coordination in distribution channels: a dynamic perspective," European Journal of Operational Research, vol. 240, no. 2, pp. 401-414, 2015.

[23] S. Taboubi and G. Zaccour, "Impact of Retailer's Myopia on Channel's Strategies," in Optimal Control and Differential Games, vol. 5 of Advances in Computational Management Science, pp. 179192, Springer US, Boston, MA, USA, 2002. 
[24] W.-Y. K. Chiang, "Supply chain dynamics and channel efficiency in durable product pricing and distribution," Manufacturing and Service Operations Management, vol. 14, no. 2, pp. 327-343, 2012.

[25] G. J. Gutierrez and X. He, "Life-cycle channel coordination issues in launching an innovative durable product," Production and Operations Management, vol. 20, no. 2, pp. 268-279, 2011.

[26] L. Lu, Q. Gou, W. Tang, and J. Zhang, "Joint pricing and advertising strategy with reference price effect," International Journal of Production Research, vol. 2016, no. 17, pp. 1-21, 2016.

[27] Q. Zhang, J. Zhang, and W. Tang, "A dynamic advertising model with reference price effect," RAIRO Operations Research, vol. 49, no. 4, pp. 669-688, 2015. 


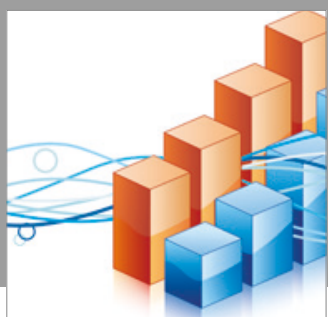

Advances in

Operations Research

vatersals

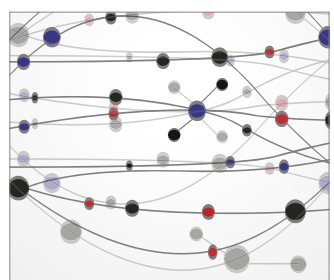

\section{The Scientific} World Journal
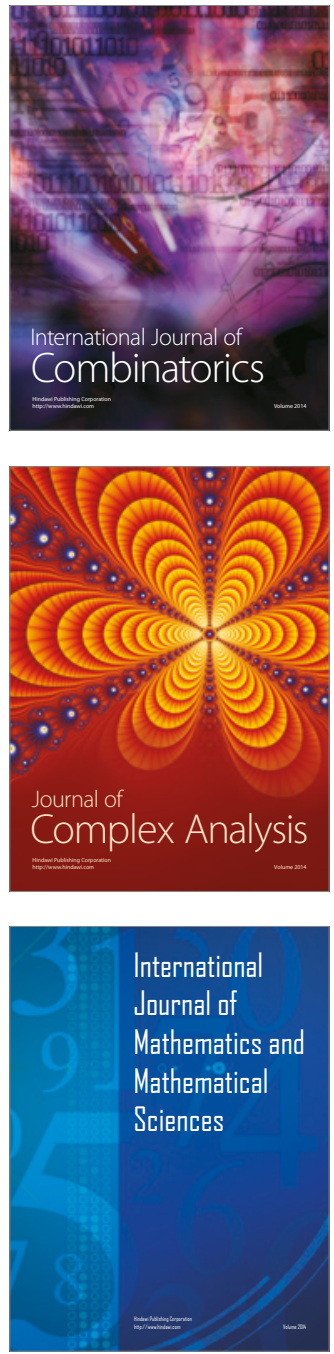
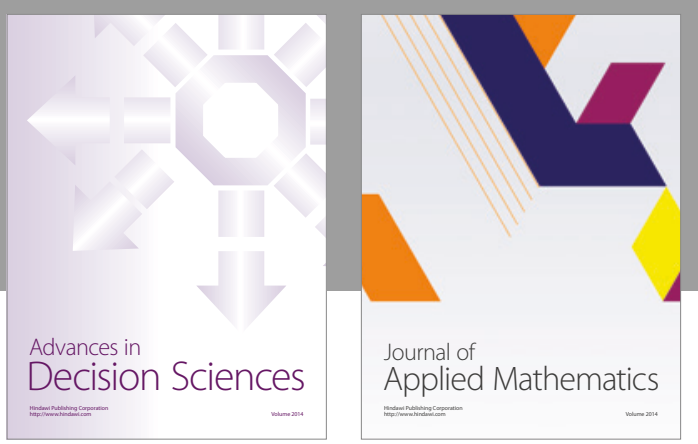

Algebra

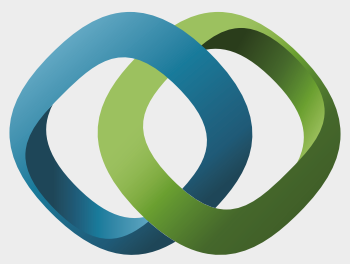

\section{Hindawi}

Submit your manuscripts at

https://www.hindawi.com
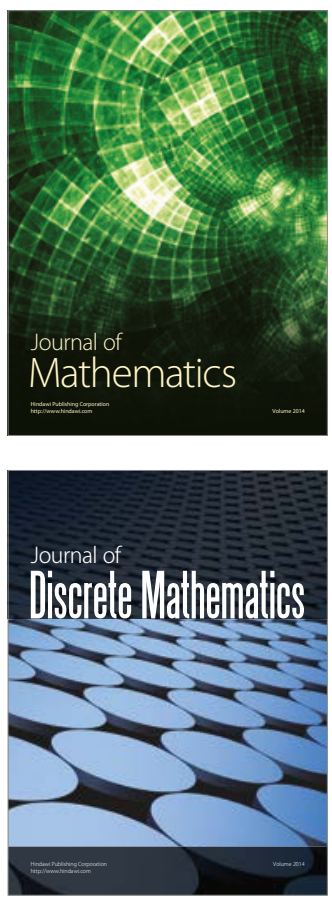

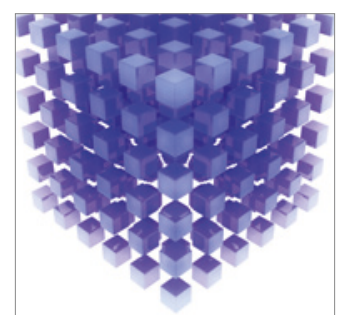

Mathematical Problems in Engineering
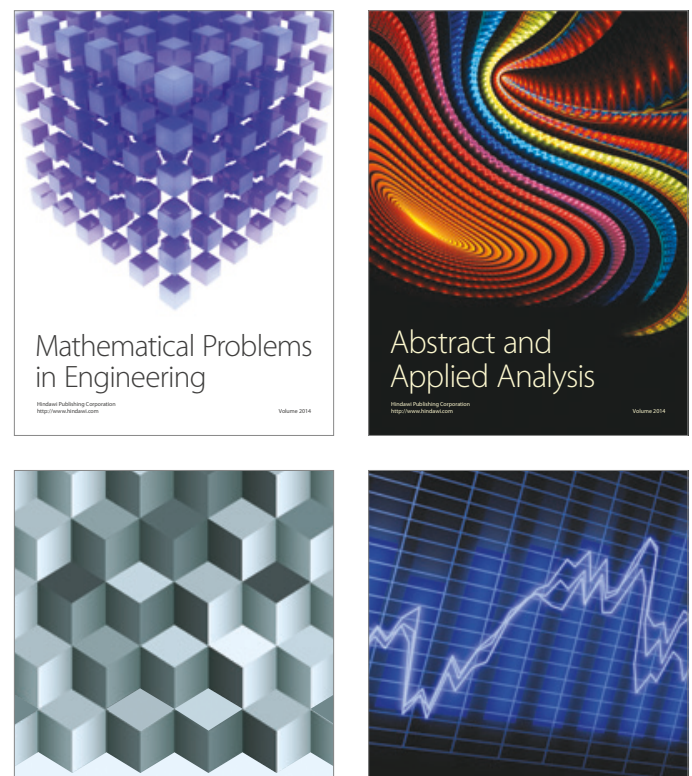

Journal of

Function Spaces

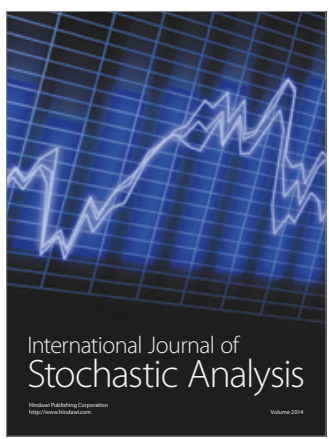

Probability and Statistics
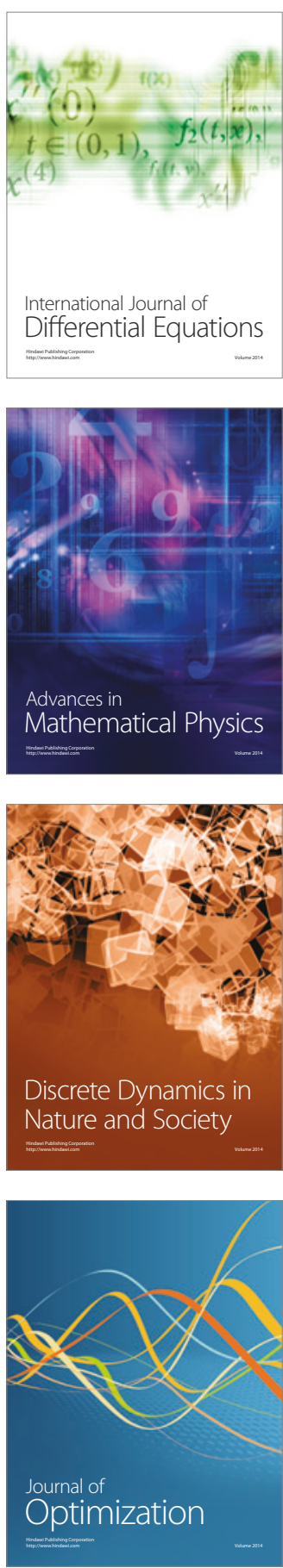